clusions reached by its aid are human productions, subject to change at any and every time. If these two ideas are constantly applied in our work, science will no longer be lacking in human interest; for it will be found to have been able to satisfy the human needs which called it into being, and will be found also to be as much a work of human, free, creative imaginative art as is the Iliad, the Venus of Milo, the Madonna of Raffael, or a Wagner opera.

\title{
CHEMICAL THEORY IN THE HIGH SCHOOL COURSE.
}

\author{
BY ROY FrYeR, \\ Of the Sacramento High School. \\ [CONTINUED FROM THE NOVEMBER NUMBER.]
}

I see no reason why the law of Boyle and also that of Charles may not be omitted altogether from the elementary course in chemistry. There are very few experiments where we use them in calculations and results almost as good can be obtained without them. When pupils are required to apply these laws to experiments, the added complexity will often cause them to lose sight of the point of the experiment. This objection may not hold so well in those schools where chemistry is taken after physics. Unless this be the case both may well be postponed. Should one wish to perform an experiment involving calculations based upon these laws, their formula could be used without any attempted explanation of their action. Bradbury in his recent textbook adopts this method, these laws being placed in the appendix, where they can be referred to when necessary.

The natural place for the periodic law is the last of the course when the properties and relations of the most important elements are well understood. The pupil now sees that they have been arranged according to law. He sees that the periodic law is the best classification which can be made, and the similarity of the elements studied together is proof of the truth of the law. It now presents many wonderful features to the student, especially in its relationship to the discovery of new substances. It adds an interest to the work which has been covered when he sees the system with which all of the elements fit into one another, and forms an agreeable conclusion to the work which he has done.

We can not well give a year of chemistry without something 
of the atomic theory. Its conception marked the beginning of modern chemistry and we now believe it almost as thoroughly as we do the facts of chemistry. Its history and its many applications are important to us, but there are some things in connection with it which are utterly useless in high school instruction.

Many things appear self-evident to us which are not intelligible to a pupil. A topic can not be made too clear to him. $\mathrm{He}$ may have the appearance of understanding and perhaps thinks he does for a time, but it need occasion no surprise if at any time he shows that he knows little or nothing about it.

So in presenting the atomic theory the simplest presentation we can give is the best. The average pupil who thoroughly understands everything in regard to the atomic theory at the close of a high school year, as he found it from whatever text-book treats it most fully, three months later will in all probability remember only its barest details. He will remember that there is stipposed to be such a thing as an atom. He will have some idea of the grouping of atoms to form molecules. He will probably know also that each atom is assumed to have a definite weight. He will probably recognize Avogadro's hypothesis as something he has met before but will be utterly unable to tell anything further about it.

The points which he remembers are those which served to correlate his work, and hence were impressed on his memory most forcibly. Beyond the elementary points which he will remember, I think there is no text-book written in a style clear enough to give the pupil a good conception of what it attempts to explain. His reasoning powers are not yet sufficiently developed to understand these processes as they are described. $\mathrm{He}$ is helpless and independence is discouraged rather than promoted. Explanations fall upon the teacher and after considerable time he is finally made to understand the various metheds of obtaining atomic and molecular weights. But they are dry to him, they do not produce a deep impression and are soon forgotten. A feeling of relief comes to him when he is through with them and again into some part of chemistry which he can enjoy.

This being the case, what good reason is there for the spending of time upon the vapor density method, the boiling and freezing point method, the relation between specific heat and atomic mass, or any other way of determining atomic or molecular masses. 
These are important and have their place, but there are other topics much more important to the chemistry pupil at this time: A few simple facts in regard to the atomic theory serve to explain the laws of definite and multiple proportions, of combination of gases by volume, of conservation of mass, of valence, of isomerism or to make any of the applications we usually make of it. Anything beyond this is useless at this time. Given in the simplest way it may come early in the course and we may lay as much stress upon it as we please without fear of going beyond the minds of the pupils.

Occasionally there is an exception to what has been said. A thoughtful pupil will ask why atomic weights are not the same as equivalent weights or how atomic weights have been determined, before his attention has been directed to it. Of course such a pupil should be encouraged. His mind is in advance of the average and if all were of this character chemistry teaching might even become more complex than it is at present. But it is to the pupil below the average that our attention must be mainly directed; those above the average under normal conditions will take care of themselves.

There remains the theory of Ionization or Electrolytic Dissociation. This theory, notwithstanding its rapid rise and almost universal adoption is still in a somewhat unsettled state. I know of no better way to present it to you than by giving the opinions of some who are well qualified to judge it.

Professor Jones of John Hopkins says in the preface of his "Elements of Inorganic Chemistry": "Take the theory of Electrolytic Dissociation, which to-day is as well established as many of of our laws of nature. It has shown us that it is the ions and not the atoms which are the active agents chemically. If the student is taught the contrary in the early stages of his work, later this must all be unlearned and we know how difficult it is to correct first impressions. If we ask the question, why continue to teach chemistry from a purely atomic standpoint after it has been shown not in accord with facts, about the only answer is that it is perhaps a little simpler than the chemistry of ions. This reply must on reflection be regarded as highly unsatisfactory. If a student can form a conception of an atom as the smallest indivisible particle of matter, would it be very difficult for him to form a conception of an atom carrying an electrical charge? Indeed it would be no more difficult than to add to the conception 
of a piece of metal the charge which it carries when electrical energy has been supplied to it, and we do not hesitate in physics to ask him to take this step. Further, since we know that it is the ion and not the atom or molecule is the factor which enters into most chemical reactions, we should insist upon it because it is true."

Professor Jones does not change ony of the older theories except as would naturally follow from the adoption of this theory. Other writers of recent high school text-books as Newell or Hessler and Smith while not making a pretense of basing their works upon this theory as does Professor Jones, treat it about as fully.

In order to show that their belief is not yet universal, I will quote from an article written by Professor Louis Kahlenberg of the University of Wisconsin: "In the face of the enthusiasm shown by the adherents of the dissociation theory and the voluminous material they have published, it is no wonder that teachers are often made to feel that they are entirely behind the times, unless they teach their chemistry, with the theory of electrolytic dissociation as the backbone of it, and in general explain the chemical, physical, and physiological behavior of solutions from the standpoint of the dissociation theory. But the teacher of secondary schools was not alone in this; university professors and other investigators of note in physics, chemistry, and physiology were looked at askance and even pitied because they could not see what Lothar Meyer called das wild Heere der Ionen and follow them. in their gambols. There are now at hand abundant well established facts that show that the theory of electrolytic dissociation is entirely inadequate, in reality untenable. $* * *$

"The teacher who has not hitherto seen fit to bring the theory of electrolytic dissociation to the notice of his pupils, certainly has no good reason for doing so now, for he can not be classed as being behind the times if he omits mentioning the theory."

In reply to a question from this association as to what prominence should be given to the study of the ionic theory, Professor Stillman of Stanford University has said: "The theory of electrolytic dissociation should be elucidated in so far at least as necessary to explain the common reactions of acids and bases and the common reactions of salt solutions. I do not think it practicable to consider it in an elementary course from a quantitative point of view (velocity, electrical charges, etc.)." 
To a similar inquiry addressed to the University of California, Professor Blasdale has answered: "The introduction of the ionic theory we consider inadvisable unless the instructor has a comprehensive knowledge of the subject and unless he is firmly convinced that he can materially add to his students' understanding of the chemical phenomena by doing so."

Without giving any further views on the subject we already have sufficient reasons for treating the theory in almost any way we see fit. I have quoted four distinct and different opinions substantially, as follows: (I) We can base all our chemistry on it because it is true. (2) We can use it with moderation for the purpose of explaining common reactions. (3) We may omit it if we feel that our own knowledge of it is not comprehensive or if it does not materially add to the students' understanding of chemical phenomena. ((4) We may omit it entirely because it is untrue.

I shall not attempt to establish any of these opinions and will only add some personal views on the question. The theory is now taught in our two universities as it is in most of the leading ones. Therefore any work we do upon it if done in the proper way is directly in line with the work of those who continue their study of chemistry. Owing to the general belief in the theory and owing to the fact that the student who does further work in chemistry will use it, it should be given some attention, but the pupil should be made to fully understand that it is a theory and can not be proven or disproven by facts.

In treating it we should follow much the same method as that used in the atomic theory. With the atomic theory time spent upon an extensive study is unnecessary so here any discussion beyond the statement of the theory itself and the applications of it to electrolysis, solution, reactions, or any other common processes which it explains is out of place. Just this will probably be sufficient to call into play the patience and tact of the teacher, as, like theory in general, it can not be grasped by the average pupil from reading text-books but must be elaborated and discussed at length before it is made clear. It is offered as a simple explanation of certain phenomena, but it is an explanation which itself may need to be explained before it can be made to affect the pupil. However if its application to the sis:ple processes is made clear the pupil who studies chemistry further should find this knowledge useful to him, and he will have 
an opportunity to study it more deeply. The pupil whose chemistry ends with the high school will not have spent much time upon a topic for which he would probably find no future use.

In concluding that course is best which contributes most to general information and culture by acquainting the pupil with a wide range of chemical facts, while at the same time it trains his powers of observation and of reasoning from those observations. This course should include the fundamental principles but not the more complex ones of theoretical conception. This will well serve as a college preparation if the teacher is well informed, and if he correlates the various parts and emphasizes fundamental principles by sufficient applications. Method of teaching is far more important than the subject matter itself. Professor Talbot of the Massachusetts Institute of Technology states that with such a basis the college instructor can develop the more advanced theories and conceptions knowing that the pupil can draw upon his own fund of knowledge for instances in which these abstract conceptions find application.

Readers of papers for this association were asked to be constructive rather than destructive, to suggest changes for the better rather than to attempt to destroy present standards.

With this aim in view I will just call your attention to Lassar Cohn's "Chemistry in Daily Life" with which you are probably all familiar. It is nearly the size of the average high school chemistry. It treats of all the common chemical processes which occur in our bodies, in nature, and in manufacturing, but without any attempted explanation of chemical theory. It is not a textbook and was not written as such. Yet it presents a great many features which a text-book might adopt. In fact, with a few changes a good chemical course could be based on this book. There would have to be suitable laboratory work to accompany it. Some chenical theory could be added where it would seem to aid the work, but the amount introduced would need be but. little. Such a course would certainly be instructive and usefni. At any rate, the subjects discussed by this book as it now stands. can well occupy some of the time we ordinarily devote to chemical theory. 